\title{
Constitucionalismo cosmopolita Cosmopolitan constitutionalism
}

\author{
Constanza Núñez Donald \\ Universidad de Chile \\ ORCID ID 0000-0003-0152-9339 \\ cnunez@derecho.uchile.cl
}
Cita recomendada:
Núñez Donald, C. (2020). Constitucionalismo cosmopolita. Eunomía. Revista en Cultura de la Legalidad,
18, pp. 214-238.
doi: https://doi.org/10.20318/eunomia.2020.5274

Recibido / received: $27 / 06 / 2019$

Aceptado / accepted: 08/01/2020

\section{Resumen}

El presente artículo tiene por objetivo caracterizar al constitucionalismo cosmopolita como un discurso específico dentro del lenguaje constitucionalista en la esfera internacional y, a la vez, destacar sus principales rasgos como proyecto normativo transformador. Para ello se realiza una reconstrucción de sus fundamentos y se desarrollan sus elementos definitorios.

\section{Palabras clave}

Constitucionalismo cosmopolita, filosofía del Derecho Internacional, constitucionalismo internacional.

\section{Abstract}

The article has an objective to characterize cosmopolitan constitutionalism as a specific discourse in the international scenario within constitutional approaches and, at the same time, to highlight its principal features as a transformative and normative project. It is made through a reconstruction of its foundations and by typifying its defining elements.

\section{Keywords}

Cosmopolitan constitutionalism; international legal philosophy; international constitutionalism.

SUMARIO. 1. Introducción. 2. Los usos descriptivo y prescriptivo del lenguaje en la esfera internacional y el lugar del constitucionalismo. 3. Constitucionalismo cosmopolita como proyecto normativo. 3.1. Constitucionalismo y cosmopolitismo. 3.2. Concepto y características del constitucionalismo cosmopolita. 3.2.1 Constitucionalismo cosmopolita como proyecto transformador y crítico. 3.2.2. Fundamentos conceptuales y empíricos. 3.2.2.1 Vocación expansiva del constitucionalismo. 3.2.2.2 Vocación histórica del constitucionalismoGiro cosmopolita de la legitimidad constitucional. 3.2.3. Importancia de los derechos, la democracia y Estado de Derecho. 3.2.4. Heredero de una tradición en la historia de las ideas políticas 4 . Conclusiones. 


\section{Introducción}

En las últimas décadas hemos visto que el lenguaje constitucional es utilizado indistintamente para intentar enfrentar los desafíos de la globalización y la fragmentación del Derecho Internacional y también para explicar los fenómenos de integración supranacional o los rasgos de los organismos de protección de derechos humanos. En este escenario, por tanto, resulta complejo distinguir nítidamente los contornos de los diferentes debates que se suscitan con ocasión de la utilización del vocablo "constitucionalismo» cuando se aplica al debate internacional y, por ello, suelen existir confusiones conceptuales.

En efecto, en los estudios académicos es posible encontrar expresiones tales como «constitucionalismo global» ${ }^{1}$, "constitucionalismo transnacional» (Neves, 2013), «constitucionalismo mundial» (MacDonald \& Johnston, 2005), "constitucionalismo multinivel» (Pernice, 2012), "metaconstitucionalismo» (Walker, 2002) y "constitucionalismo cosmopolita», que es el concepto objeto de este estudio. Las diversas acepciones son utilizadas algunas veces como sinónimos y otras como aproximaciones diversas para abordar la cuestión del uso del enfoque constitucionalista más allá de los márgenes estatales (Schwöbel, 2011, p. 2). Esto es «una prueba de que el constitucionalismo internacional es todavía un concepto "esencialmente controvertido» sobre el que no existe una versión única» (Rodrigo, 2014, p. 13).

El objetivo de este trabajo es examinar los usos del lenguaje constitucional ${ }^{2}$ más allá de los márgenes estatales y, en este contexto, caracterizar adecuadamente el concepto «constitucionalismo cosmopolita» frente a otros proyectos 0 reconstrucciones conceptuales que utilizan la aproximación constitucionalista en relación a la dimensión internacional.

Para cumplir este objetivo, en primer lugar, se propondrá una tipología de enfoques de utilización del lenguaje constitucionalista y se situará al constitucionalismo cosmopolita. Luego, se definirá específicamente el constitucionalismo cosmopolita y se reconstruirán sus fundamentos y principales rasgos definitorios.

2. Los usos descriptivo y prescriptivo del lenguaje en la esfera internacional y el lugar del constitucionalismo

La distinción que se propone a continuación sobre el uso del lenguaje constitucional en la esfera internacional, entre enfoques descriptivos y normativos, se basa en destacar los objetivos que se persiguen cuando se utiliza el lenguaje constitucionalista más allá del Estado. Las aproximaciones descriptivas buscan encontrar rasgos constitucionales en las estructuras y normas internacionales, destacando la existencia de un proceso de «constitucionalización» de la esfera internacional, o mostrando la existencia de una «Constitución» del mundo, mediante la utilización de herramientas argumentativas tales como la analogía. Por su parte, los enfoques normativos, si bien también parten de la base del análisis de la realidad internacional (donde se analizan

\footnotetext{
${ }^{1}$ Esta es la acepción más utilizada y es definida por Peters como «una agenda que identifica y defiende la aplicación de principios constitucionalistas en la esfera jurídica internacional», (Peters, 2018, p. 3). Esta expresión engloba, en general, las diferentes aproximaciones que sobre esta cuestión se están desarrollando en el ámbito internacional, posicionándose como un ámbito de estudio interdisciplinar. Véase al respecto la exposición de motivos de creación de la revista «Global constitutionalism» (Wiener, Lang, Tully, Maduro, \& Kumm, 2012). La expresión es utilizada también en (Schwöbel, 2011).

2 Un examen del panorama puede revisarse también en: (Schwöbel, 2011); (Lang \& Wiener, 2017); (Diggelmann \& Altwicker, 2008) y, en español (Rodrigo, 2013).
} 
los procesos de constitucionalización como tendencias que favorecen el desarrollo del paradigma constitucionalista), este enfoque es sobre todo prospectivo y crítico, poniendo especial énfasis en aquellos aspectos que deben desarrollarse a futuro para que el constitucionalismo se transforme en una realidad aplicable más allá del Estado, proponiendo o sugiriendo criterios para la solución de problemas referentes a la creación y legitimación del Derecho que impactan no solo a nivel internacional, sino también a la comprensión del constitucionalismo en general ${ }^{3}$. Dentro de los enfoques normativos se encuentra el constitucionalismo global orgánico ${ }^{4}$ y el constitucionalismo cosmopolita.

La caracterización del debate que se propone es una de las formas de organizarlo, existiendo otras que tienen aproximaciones metodológicas diferentes. Así, por ejemplo, una de las estrategias ha sido dividir el debate entre aproximaciones funcionalistas, normativas y pluralistas (como es el caso del enfoque de la revista Global Constitutionalism) (Wiener, Lang, Tully, Maduro, \& Kumm, 2012) o quien se aproxima al fenómeno mediante el estudio de las aportaciones desde el Derecho Internacional público, distinguiendo entre constitucionalismo global societal, institucional, normativo y analógico (Schwöbel, 2011). Las aproximaciones metodológicas descritas se han centrado en poner énfasis en la estrategia argumentativa que utiliza cada escuela para reconstruir el lenguaje constitucionalista global a través del análisis de sus herramientas metodológicas (por ejemplo, la analogía) y objeto de estudio (por ejemplo, sociedad o instituciones). En el caso de la distinción entre aproximaciones funcionalistas, normativas y pluralistas, si bien se acercan a la clasificación aquí propuesta (en la medida en que distingue entre quienes buscan «mapear» y «contornear» el constitucionalismo internacional) (Wiener, Lang, Tully, Maduro, \& Kumm, 2012, p. 8), no da cuenta suficientemente de la vocación de los proyectos, en la medida en que, por ejemplo, se sostiene que entre estas diferentes aproximaciones no habrían diferencias sustantivas, sino más bien de enfoque $^{5}$. Sin embargo, las diferencias si son sustanciales y están dadas por la influencia de las aproximaciones filosóficas en las que se sustentan, por el rol que los derechos humanos juegan en las reconstrucciones constitucionalistas y, por sobre todo, si se trata de construcciones teóricas que buscan delinear criterios nuevos y específicos para la dimensión internacional (bajo el paraguas del constitucionalismo, como es la aproximación del constitucionalismo cosmopolita) o bien, se conforman con trasladar los principios clásicos del constitucionalismo sin intermediaciones (como hace la estrategia descriptiva).

En este sentido, las ventajas del enfoque propuesto para clasificar las aproximaciones constitucionalistas, es que permite resaltar cuáles son los objetivos que se buscan al utilizar el lenguaje constitucional más allá del Estado: mientras que para las aproximaciones descriptivas el énfasis estará en comprender la configuración internacional a través de las categorías clásicas del constitucionalismo, el enfoque

\footnotetext{
3 La distinción entre enfoques normativos y descriptivos para analizar el debate sobre el constitucionalismo global es utilizada también por Klabbers, 2009, para definir los objetivos de su libro.

${ }^{4}$ También en un sentido normativo, pero diferente del constitucionalismo cosmopolita, encontramos la propuesta de un constitucionalismo global orgánico. Aunque es una propuesta concreta de Schwöbel (2010; 2011), algunos de sus elementos pueden ser encontrados también en ciertos planteamientos de Koskenniemi (aunque él no califica su propuesta como constitucionalista, véase: Koskenniemi, 2005; 2010). El constitucionalismo orgánico global se presenta como una alternativa al discurso del constitucionalismo global, donde se destacan tres críticas a ese discurso: 1) excesiva centralización del poder; 2) lo problemático que resulta la designación de ciertos valores compartidos asociados a la idea de derechos humanos universales y; 3) se plantea que existe una traslación irreflexiva de los postulados del constitucionalismo liberal a la dimensión internacional. Para enfrentar estas críticas el constitucionalismo global orgánico se presenta como un «continente vacío» que permitiría el desarrollo de disputas de poder en condiciones de igualdad.

${ }^{5}$ Se sostiene que «la diferencia principal entre estas tres escuelas es pragmática antes que filosófica» (Wiener, Lang, Tully, Maduro, \& Kumm, 2012, p. 8).
} 
normativo busca sobre todo plantearse como un nuevo paradigma para responder a los problemas globales bajo la lógica del discurso constitucionalista ${ }^{6}$.

Para realizar estas distinciones y caracterizar al constitucionalismo cosmopolita en el contexto general de estos debates, me parece especialmente útil acudir a la diferenciación entre "Constitución», "Constitucionalismo» y «Constitucionalización» (Peters \& Armigeon, 2009, pp. 386-387; Peters, 2008, pp. 210-215; Bodansky, 2009, pp. 565-584) ${ }^{7}$.Mientras que el enfoque descriptivo se ha centrado en el desarrollo de los conceptos Constitución y Constitucionalización de la comunidad internacional, el término Constitucionalismo, puede ser identificado con la dimensión normativa, en tanto éste es tratado como un proyecto político, pero esta vez aplicado más allá de los márgenes estatales.

En la aproximación que hemos caracterizado como «descriptiva», encontramos dos enfoques: uno se refiere a la existencia de una Constitución del mundo, y otro se refiere al estudio de los procesos de Constitucionalización del Derecho Internacional ${ }^{8}$. Ambas aproximaciones lo que hacen es reconstruir fenómenos empíricos vinculados al desarrollo y evolución normativa del Derecho Internacional bajo la óptica del lenguaje constitucional. Uno de los puntos de partida de ambas aproximaciones (Constitución y Constitucionalización) es la consideración básica de la existencia de una comunidad internacional, es decir, una «formación jurídica que, en conjunto, asume la responsabilidad de asegurar los fundamentos de la existencia de la humanidad» (Tomuschat, 2010, p. 100) ${ }^{9}$. La existencia efectiva de esta comunidad internacional se argumenta tanto en aspectos normativos, como mediante el análisis de desarrollos histórico-institucionales vinculados al Derecho Internacional. La idea de que el consentimiento ya no es la base de legitimidad para la existencia de obligaciones resulta central para la idea de comunidad internacional. Tomuschat, por ejemplo, fundamenta esta idea en la existencia de intereses comunes globales que van más allá de la agrupación de intereses estatales y que ya no son solo manifiesto de un interés filosófico, sino que tienen una manifestación concreta, por ejemplo, en las normas de ius cogens y las obligaciones erga omnes ${ }^{10}$.

\footnotetext{
6 Como toda clasificación que tiene por objeto ordenar un debate, existirán aproximaciones que probablemente no puedan ser identificadas con total nitidez dentro de una u otra categoría. Por ejemplo, la propuesta de (Kleinlein y Kadelbach, 2007) en algunos de sus extremos puede ser entendida como descriptiva de la constitucionalización, pero también va más allá en cuanto busca ofrecer parámetros para entender qué se puede entender normativamente como Constitución en el ámbito internacional (alejándose, por tanto, de la estrategia de la analogía doméstica). Por otra parte, los enfoques seleccionados son jurídicos, caracterizados por tener como objeto de estudio el conjunto de normas del orden internacional, así como criterios para su producción y aplicación. Existen otros enfoques para abordar esta cuestión como, por ejemplo, aproximaciones sociológicas, que ponen especial énfasis a la forma en que se conforma la sociedad internacional como una comunidad internacional, véase: (Atilgan, 2017) que trata al constitucionalismo global como paradigma cultural; (Diggelmann \& Altwicker, 2008) desde la perspectiva del constructivismo social y; (Teubner, 2014), desde la perspectiva del constitucionalismo societal.

7 Estos tres conceptos también son relevantes para delimitar los debates en la revista Global Constitutionalism, (Wiener, Lang, Tully, Maduro, \& Kumm, 2012, pp. 4-6).

${ }^{8}$ Ambos enfoques pueden diferenciarse, a su vez, de aquel que estudia el impacto de las normas internacionales en el Derecho Constitucional «interno». Este proceso se da por la apertura constitucional al Derecho Internacional, lo que tiene consecuencias tanto en términos formales como sustantivos que se manifiestan en una cada vez mayor aplicación jurisdiccional de normas internacionales. Sobre el proceso de interacción entre ambas dimensiones normativas, véase especialmente el concepto de «Estado constitucional cooperativo» (Häberle, 2013, p. 261).

9 Sobre la influencia de la idea de comunidad internacional en el debate contemporáneo de constitucionalismo global, véase: (Bogdandy, 2006).

10 Junto con Tomuschat, se reconoce que forman parte de la «international community school» autores como (Mosler, 1980; Simma, 1994). Véase: (Fassbender, 2010, p. 132).
} 
En este sentido, tanto para el discurso de la Constitucionalización como de la Constitución, el desarrollo normativo de postguerra, vinculado a la protección internacional de los derechos humanos resulta central. En este sentido, a diferencia de la aproximación normativa (que, como veremos, tiene antecedentes en el pacifismo jurídico), son teorías que se comienzan a desarrollar sólo con la llegada del S. XX a partir de las transformaciones que se van desarrollando en el Derecho Internacional.

En el ámbito internacional el uso del vocablo Constitución, se ayuda de la distinción entre Constitución escrita y no escrita y material e inmaterial, y pese a existir diferencias en torno a qué se entiende, en concreto, por Constitución en el ámbito internacional ${ }^{11}$, es un enfoque que pretende diferenciarse del discurso de la mera legalización internacional, en cuanto se concibe a la Constitución como un estatuto creador y constitutivo de autoridad pública legítima (Klabbers, 2009, p. 9). Dentro de estas aproximaciones la principal diferencia radica en el contenido que se asigna a la Constitución. Así, hay quienes la identifican con la Carta de la ONU (Fassbender, 1998; Dupuy, 1997), y otros, quienes apuestan por reconstruir el concepto de Constitución de la comunidad internacional a través de la identificación de un conjunto material con características constitucionales (principios y reglas), que darían cuenta de la existencia de una Constitución no escrita de la comunidad internacional (Rodrigo, 2018; De Wet, 2006; Kadelbach \&Kleinlein, 2007).

En relación a la Constitucionalización, este enfoque estudia la forma en que estructuras y organizaciones van adquiriendo características y cumpliendo funciones constitucionales ${ }^{12}$. Aquí también podemos encontrar diversos enfoques y estrategias, pero una característica común es que quienes suscriben esta aproximación utilizan la analogía como herramienta metodológica para encontrar similitudes entre las estructuras constitucionales nacionales e internacionales ${ }^{13}$, es decir, se encuentran patrones en la esfera internacional que son familiares a las estructuras constitucionales nacionales y, a partir de allí, se aplican conceptos conocidos a nivel interno a la esfera internacional. Así, por ejemplo, es común dentro de estas aproximaciones analizar en clave constitucional la estructura de algunas organizaciones internacionales, como la OMC, el GATT o la OIT.

Cuando se habla de constitucionalización en este ámbito, se utiliza el lenguaje constitucional para describir a una organización que tiene un tratado fundacional, que tiene autonomía normativa y que cumple algunas funciones constitucionales (Wet, 2006 , p. 53). En este sentido, los análisis tienden a ser sectoriales, por ello se sostiene que este análisis es "micro-constitucional" (Peters, 2010, p. 233). Un rasgo de este enfoque consiste en resaltar la imposibilidad de hablar de Constitución (Walter, 2001), pues «el conjunto no aparece como una estructura de organizaciones, sino como una simple acumulación de desarrollos asimétricos y asincrónicos, sin duda abierta a procesos de comunicación, pero sin coordinación política» (Gutiérrez, 2010, p. 90).

La aproximación descriptiva, como la hemos descrito, ha sido objeto de numerosas críticas, respecto de las cuales el constitucionalismo cosmopolita se plantea como alternativa.

\footnotetext{
11 Un estudio sobre los diferentes alcances del concepto de Constitución en ámbito internacional en: (Diggelmann \& Altwicker, 2008).

12 En la clasificación aportada por (Diggelmann \& Altwicker, 2008, p. 632), la perspectiva de la constitucionalización correspondería a la estrategia de "correspondencia» en tanto se encarga de buscar funciones o elementos constitucionales en la esfera internacional.

${ }^{13}$ Este es un constitucionalismo global que Schwobel califica como «analógico» (Schwöbel, 2011, p. 43).
} 
Por una parte, se sostiene que esta perspectiva desconoce la realidad de fragmentación que está presente en el escenario internacional (Diggelmann \& Altwicker, 2008, p. 624) ${ }^{14}$. Esta fragmentación, aunque no necesariamente represente una imposibilidad para este tipo de discurso (como veremos, el constitucionalismo cosmopolita se presenta también como una solución a este problema), exige al menos la necesidad de desarrollar criterios que permitan realizar un análisis de conjunto que permita identificar una "unidad en la "variedad"» (Peters, 2010, p.247). Estos criterios se encuentran ausentes en la aproximación descriptiva.

Por otra, se sostiene que esta perspectiva no cuenta con criterios unificados para identificar qué se está diciendo cuando se está utilizando el vocablo Constitución. En efecto, la utilización de esta palabra tiene diferentes significados. Esto no significaría un problema si se explicitaran los conceptos de Constitución que se encuentran tras las diversas aproximaciones ${ }^{15}$; el problema sí está, cuando el lenguaje del constitucionalismo se desnaturaliza para asimilarlo a cualquier práctica jurídica. Respecto de esta cuestión, por ejemplo, La Torre advierte que lo que ha ocurrido con la aparición del discurso de la constitucionalización, es que el lenguaje constitucional se ha utilizado para describir cualquier realidad normativa en el plano internacional, «liberalizando» el concepto de Constitución (La Torre, 2016, p. 9). Uno de los problemas de la utilización del lenguaje constitucional para describir cualquier realidad que pretenda regular el poder, es que la autoridad de las normas se pretende imponer por la racionalidad autoevidente de sus afirmaciones (Loughlin, 2010, p. 68). Es decir, en este punto se cuestiona que se utilice el lenguaje constitucional para dotar de una falsa legitimidad a las prácticas internacionales, sin que esté asociado a ello un discurso normativo más denso que el de la mera regulación. Para utilizar el concepto Constitución o constitucionalismo, habría que agregar una dimensión simbólica vinculada a un discurso sobre ejercicio de la autoridad legítima.

Finalmente, se sostiene que la perspectiva descriptiva carece de un valor explicativo adecuado de la realidad internacional, no solo en cuanto a lo referido a la fragmentación, sino sobre todo por la existencia de tendencias contrarias que apuntan en un sentido diverso al del lenguaje constitucional, por lo que la base factual sería tan contradictoria que sería imposible comprenderla bajo la óptica del constitucionalismo (Diggelmann \& Altwicker, 2008, pp. 624-631).

El potencial de estas tres críticas evidencia que no basta con sostener la existencia de tendencias favorables hacia la constitucionalización. Para que el discurso tenga capacidad explicativa también deberá hacerse cargo de proveer criterios para comprender aquellos aspectos que se escapan de la reconstrucción y guiar el análisis hacia la incorporación de las tendencias disruptivas. En este sentido, a partir de estos puntos es posible extraer los elementos que las perspectivas normativas (como es el constitucionalismo cosmopolita) adicionan al uso del lenguaje

\footnotetext{
${ }^{14}$ Con fragmentación se hace referencia a la existencia de múltiples regímenes normativos con sus propias reglas e instituciones (Derecho del mar, Derechos humanos, Derecho ambiental, Derecho comercial, etc.), altamente especializados y que se han creado con relativa ignorancia de las actividades legislativas, principios y prácticas de los campos adyacentes (véase: CDI, 2016, párr. 8). El fenómeno de la fragmentación ha sido una cuestión que ha preocupado especialmente a los juristas internacionalistas. Para estudiar el asunto y proponer criterios para su solución se creó un grupo de estudios en la Comisión de Derecho Internacional de Naciones Unidas, véase: (CDI, 2006).

${ }^{15}$ Como excepción podemos mencionar el caso de (Rodrigo, 2018), que aunque utiliza una aproximación descriptiva, otorga criterios para poder determinar qué se entiende por una norma internacional con características internacionales. Sin embargo, los criterios propuestos tienen el problema de terminar identificando material constitucional teniendo como referencia únicamente el Derecho Internacional Público, sin considerar que el constitucionalismo internacional o global puede tener un espectro más amplio de normas que incorporen dimensiones nacionales, internacionales, transnacionales y cosmopolitas.
} 
constitucionalista en la esfera internacional: un discurso donde no sólo se argumente en torno a la realidad «positiva» (Kumm, 2013, p. 610), sino que se den razones para sostener si el proceso de constitucionalización es (o no) deseable y que se construye con carácter prospectivo, como una idea sobre cómo debe regularse el poder en la esfera internacional bajo el paradigma constitucionalista (Kumm, 2013, p. 610). Como señala Habermas:

«Quienes aboguen por una constitucionalización del Derecho internacional, si no quieren descartar totalmente la democracia, se ven obligados a desarrollar al menos modelos para un arreglo institucional que pueda garantizar una legitimación democrática las nuevas formas de gobernación de los asuntos en espacios que carecen de fronteras» (Habermas, 2009, p.109).

\section{Constitucionalismo cosmopolita como proyecto normativo}

\subsection{Constitucionalismo y cosmopolitismo}

Para comprender el concepto de constitucionalismo cosmopolita, previamente es necesario especificar en qué sentido son utilizados los términos constitucionalismo y cosmopolitismo en esta reconstrucción conceptual.

Como nos advierte Comanducci $(2002 ; 2011)$ uno de los grandes problemas respecto a la definición del constitucionalismo -en general-, ha sido la falta de claridad respecto a si se habla de constitucionalismo como ideología, teoría o metodología. A grandes rasgos y, siguiendo a Ferrajoli (2011b; 2014), es posible distinguir entre un "constitucionalismo político» y un «constitucionalismo jurídico». Mientras que el constitucionalismo político hace referencia a una ideología de limitación al poder para la garantía de los derechos fundamentales, el constitucionalismo jurídico tiene como objeto de estudio del Estado Constitucional de Derecho y a partir de allí analiza el impacto que para la teoría del Derecho tiene el surgimiento de las democracias constitucionales de postguerra y, en este sentido, se trata al constitucionalismo como una teoría del Derecho (principialista, post-positivista o garantista) ${ }^{16}$.

Cuando nos referimos al "Constitucionalismo cosmopolita» trataremos al constitucionalismo como ideología o, en palabras de Ferrajoli, como "constitucionalismo político» ${ }^{17}$. Esta aproximación se utiliza porque tiene mayor capacidad explicativa del constitucionalismo cosmopolita como proyecto. Si el constitucionalismo cosmopolita es, a grandes rasgos, el proyecto político de aplicación de la lógica del constitucionalismo más allá del Estado, el sentido de la palabra constitucionalismo en el contexto de este discurso tiene que ver, sobre todo, con su carácter de ideología política que busca ciertos fines a través de determinados medios. Aunque la relación entre orígenes del poder, fines y medios en el contexto de constitucionalismo no está exenta de dificultades ( $y$ de estas divergencias trata fundamentalmente las principales tendencias contemporáneas del constitucionalismo, Mac Amhlaigh, 2016, p. 195), esto no nos impide hablar de un sentido común mínimo de lo que ha significado y significa contemporáneamente el constitucionalismo como proyecto político. Este sentido mínimo, aplicado al debate que nos ocupa, implica concebirlo como un marco o estructura de pensamiento que

\footnotetext{
16 Sobre la adecuación de estas denominaciones para tratar la cuestión del constitucionalismo como Teoría del Derecho, véase los diferentes artículos de la revista Doxa n 34 (2011). Véase también el debate entre (Ferrajoli \& Ruiz Manero, 2012) y los estudios del libro editado por (Carbonell, 2009).

17 Este es el sentido en que autores como Zagreblesky, Fioravanti o Waldrontratan el constitucionalismo. Zagreblesky se refiere al constitucionalismo como un «ideal político atemporal» (aunque reconoce su carácter históricamente condicionado), véase: (Zagreblesky, 2013, p. 19); Fioravanti lo conceptualiza como una "corriente de pensamiento» (Fioravanti, 2014, p. 17). Véase también la caracterización de (Waldron, 2012) del constitucionalismo como ideología.
} 
involucra tres ideas: límite al poder, garantía de derechos fundamentales y autoridad legítima (Klabbers, 2009, p. 10). Estas tres ideas en el caso del constitucionalismo cosmopolita, tienen ciertas características que nos permiten caracterizarlo como un proyecto específico de constitucionalismo (como veremos).

El cosmopolitismo contemporáneo, por su parte, es heredero de una larga tradición en la historia de las ideas que se remonta a la antigüedad, se desarrolla con fuerza en la llustración y es retomado en la década de los 90' en el contexto de la globalización (Held, 2012, pp. 48-57). Este último sería el denominado cosmopolitismo «postwestfaliano». A diferencia de otros estudios que se comienzan a desarrollar en la década de los 90' para explicar el funcionamiento de la globalización (estudios de la globalización o estudios globales), el cosmopolitismo tiene un fuerte contenido prescriptivo, es decir, no es una respuesta para explicar la globalización, sino que es también una filosofía política propiamente tal (Brock \& Brighouse, 2005) ${ }^{18}$. Por tanto, en relación a la globalización, su objeto es cuestionarla y desarrollar nuevos conceptos que permitan realizar los principios cosmopolitas (Delanty, 2012). Este cosmopolitismo se denomina "post-westfaliano», porque se desarrolla en un contexto de crisis del Estado-nación, del concepto de soberanía y de la manera de entender las relaciones internacionales (Cortés \& Piedrahita, 2011, p. 226) ${ }^{19}$. Las prescripciones centrales de este cosmopolitismo son, por una parte, el desarrollo de criterios de justicia a nivel global que puedan combatir las consecuencias negativas de la globalización para el ejercicio y goce de los derechos humanos y, por otra, la creación de instituciones y políticas destinadas a regular la globalización asumiendo el nuevo escenario de debilitamiento del Estado-nación. Este es el sentido del cosmopolitismo que se vincula con el constitucionalismo en el concepto que estamos desarrollando.

Como ideal filosófico, en general, los cosmopolitas sostienen un particular análisis que "replantea las habituales connotaciones de los discursos identitarios y, en especial, de las visiones de la alteridad, defendiendo como horizonte moral relevante la humanidad en su conjunto» (Pérez de la Fuente, 2006, p. 71). Aunque el cosmopolitismo tiene múltiples ámbitos de desarrollo (morales, jurídicos, políticos y culturales), un aspecto común de esta propuesta teórica es la consideración de la relevancia de la humanidad como referente moral básico. Pese a tratarse de una filosofía de larga data, no existe un consenso único acerca del contenido preciso de una propuesta cosmopolita (Scheffler, 1999, p. 255). Sin embargo, existen tres elementos que son destacados por Held como «característicos» de cualquier propuesta que se denomine cosmopolita: (i) el individualismo igualitario, (ii) el reconocimiento recíproco y, (iii) el razonamiento imparcial (Held, 2012, p. 27). El primer elemento establece que los individuos son las unidades últimas de incumbencia moral, es decir, no los Estados u otras formas particulares de asociación, el segundo implica reconocer que todas las personas tienen igual valor moral y eso debe ser reconocido por todos; mientras que la imparcialidad se refiere a que las demandas de todas las personas deben tener derecho a un examen imparcial de deliberación (Held, 2012, p. 27). Considerando estos elementos básicos, resulta especialmente esclarecedora la definición que nos proporciona Chernilo, «el cosmopolitismo lo defino como el horizonte normativo fundamental a través del cual las sociedades modernas articulan ideas de paz y justicia que son válidas para todos los seres humanos sin exclusión» (Chernilo, 2015, p. 310).

\footnotetext{
18 En el mismo sentido (Delanty, 2012, p. 9), destaca que el cosmopolitismo puede analizarse como prescripciones de moral y política, o bien como un método para analizar el mundo. Esto no significa que no existan otras aproximaciones al cosmopolitismo, por ejemplo, como método. Esta es un aspecto del cosmopolitismo que ha desarrollado una versión de la sociología, como la de (Beck, 2005, pp. 29-51).

${ }^{19}$ Estas serían las denominadas "circunstancias" del cosmopolitismo contemporáneo (Held, 2012, p. 47).
} 
En relación a las diferentes vertientes del cosmopolitismo (moral, político, jurídico y cultural) ${ }^{20}$, el constitucionalismo cosmopolita se vincula específicamente con el denominado cosmopolitismo político y jurídico. Tanto la democracia como la ciudadanía (conceptos del cosmopolitismo político) y el imperio de la ley (concepto relevante para el cosmopolitismo jurídico), son centrales para el proyecto. No hay una desconexión entre la promesa de legitimidad y su forma jurídica. El constitucionalismo cosmopolita es un proyecto político con una determinada forma jurídica.

Conforme a los contenidos mínimos que hemos descrito de lo que implica una propuesta constitucionalista y cosmopolita, quienes desarrollan este concepto, como veremos a continuación, sostienen que existe una conexión conceptual, histórica y empírica entre ambos. Esto permite superar un problema que es posible identificar comúnmente en los discursos vinculados al constitucionalismo global y que es la fragmentación de sus argumentos: o bien se apela a la existencia de un constitucionalismo global basado en la identificación de tendencias y principios cosmopolitas, o se propone de la instauración institucional de principios cosmopolitas a nivel global. De esta manera, lo que ha ocurrido es que se desarrollan perspectivas que tienen vocación cosmopolita pero no responden a la lógica del constitucionalismo o bien son constitucionalistas pero no se basan en principios cosmopolitas (Brown, 2016). El constitucionalismo cosmopolita permite unir ambos discursos.

Aunque el término "global» es el más utilizado en el contexto de estos debates, se prefiere la denominación «cosmopolita» (además de los motivos conceptuales apuntados), porque el término «global» tiene como riesgo que se obvie el componente prescriptivo del proyecto (Cortés \& Piedrahita, 2011, p. 226), pues la denominación "global» también ha sido utilizada para hacer referencia a la realidad normativa global mercantil o, para describir los efectos de la globalización en el Derecho. En este sentido, no da cuenta de un proyecto jurídico-político inspirado en los principios del cosmopolitismo. Si eliminamos ya sea la referencia a constitucionalismo o cosmopolitismo del concepto, la promesa de autoridad legítima basada en derechos desaparece del discurso. El denominado "globalismo» ha escondido bajo una apariencia de neutralidad una determinada ideología que implica la desregulación y liberación del poder (Fariñas, 2000), todo lo contrario a los principios del constitucionalismo cosmopolita.

\subsection{Concepto y características del constitucionalismo cosmopolita}

El concepto y características del constitucionalismo cosmopolita que se desarrollan a continuación corresponden a una reconstrucción argumentativa que realiza a partir de los elementos comunes que se encuentran en diferentes propuestas de constitucionalismo global. Aunque existan diversos enfoques para desarrollar este concepto, se sostiene que es posible encontrar un núcleo común en las diversas propuestas y que nos permite hablar del constitucionalismo cosmopolita como una nueva forma de comprender el constitucionalismo en general.

En el discurso constitucionalismo cosmopolita, encontramos autores/as que han llegado a este concepto mediante reflexiones en contextos amplios de análisis sobre las relaciones entre Derecho y democracia (es decir, como parte de una reflexión teórica general en el marco de la filosofía política y del Derecho), y quienes han abordado esta cuestión como parte de reflexiones específicas sobre el carácter constitucional de la dimensión internacional. En el primer grupo encontramos a Habermas (1997; 2000; 2006; 2008; 2009; 2012a; 2012b; 2014; 2015; 2016) o

\footnotetext{
${ }^{20}$ Un desarrollo sobre las diferencias y características de estas diferentes aproximaciones en: (Arcos, 2009 y Beitz, 2005).
} 
Ferrajoli (1998; 2004; 2005; 2008; 2010; 2011; 2018). Ambos autores llegan a abordar una propuesta normativa como es la del constitucionalismo cosmopolita como parte de una teoría del Derecho y la democracia que culmina con una aspiración cosmopolita. En el segundo grupo encontramos a autores/as como Kumm (2004; 2009; 2013; 2016), Peters (2009a; 2009b; 2010; 2018), Brown (2012; 2013), Bryde (2005) o Petersmann (2013a; 2013b; 2017), quienes ponen especial énfasis en reconstruir un marco hermenéutico específico en clave constitucional para comprender la interrelación entre la dimensión internacional y la nacional.

Pese a que el punto de partida del análisis sea diferente en el desarrollo de este concepto (de lo general a lo particular, o de lo particular a lo general), e incluso las denominaciones del proyecto (postnacional, cosmopolita, global), hay rasgos comunes de esta aproximación y que se desarrollarán a continuación: (i) se llega argumentativamente al constitucionalismo cosmopolita compartiendo una aproximación normativa, presentando al constitucionalismo cosmopolita como un proyecto político transformador y crítico; (ii) se apoya en argumentos conceptuales y empíricos (en este sentido, recupera parte del discurso de la constitucionalización); (iii) se asigna un rol central a los derechos, la democracia y el Estado de Derecho y; (iv) es una tradición heredera de una larga tradición de ideas políticas, pero con ciertos rasgos particulares.

\subsubsection{Constitucionalismo cosmopolita como proyecto transformador y crítico}

La caracterización del carácter de proyecto de este concepto es explicada por Peters en los siguientes términos: el constitucionalismo cosmopolita (global en términos de Peters) es una «línea de pensamiento (una visión o perspectiva) y una agenda política que pretende la aplicación de los principios constitucionales, como el Estado de Derecho, controles y equilibrios (checks and balances), la protección de los derechos humanos y la democracia, en el ámbito jurídico internacional, para mejorar la efectividad y la equidad del ordenamiento jurídico internacional» (Peters, 2010, pp. 214-215).

Pero, a diferencia de aproximaciones como las de la constitucionalización, lo característico de este proyecto es que busca aplicar los principios del constitucionalismo tomando en consideración la realidad internacional, creando a la vez, un nuevo marco de comprensión tanto para el constitucionalismo como para la regulación internacional. El enfoque normativo viene dado por una comprensión común de lo que significa el constitucionalismo como proyecto: autoridad legítima, limitación al poder y garantía de derechos (Bryde, 2005, pp. 106) ${ }^{21}$. En este sentido, en todas las aproximaciones que se desarrollan en el marco de este discurso, se proponen o sugieren criterios para la solución de problemas referentes a la creación y legitimación del Derecho bajo el paradigma constitucionalista. Hay una mirada de futuro que busca ser transformadora y crítica.

Es transformadora en el sentido de que, pese a que se utiliza el lenguaje constitucionalista, esta mirada no cae en la «domestic analogy» como estrategia, por el contrario, se buscan desarrollar nuevos criterios (Peters \& Armigeon, 2009, pp. 389) para comprender la forma de creación y legitimidad del Derecho en la esfera internacional. En contra de un prejuicio generalizado en contra de esta doctrina, ninguna de las propuestas tiene un compromiso con un Estado mundial, pues como señala Petes «la idea no es crear un gobierno central y globalizado, sino

21 En palabras de Kumm esta comprensión mínima también puede ser descrita como «ambicioso proyecto normativo de establecimiento de la autoridad legítima entre personas que -en último términoson consideradas libres e iguales», véase: (Kumm, 2013, pp. 609). 
constitucionalizar la gobernanza global, poliárquica y multinivel» (Peters, 2008, p. 11; Ferrajoli, 2011a, p. 561; Habermas, 2006, p. 131). Por otra parte, a diferencia de la perspectiva de la constitucionalización, se busca trascender la diferenciación entre Derecho constitucional estatal e internacional, proponiendo un nuevo nivel: el cosmopolita (Kumm, 2013).

La dimensión crítica de este proyecto puede ser entendida en dos sentidos. Por una parte, en relación al propio discurso de la constitucionalización del Derecho Internacional $y$, por otra, por el carácter inminentemente crítico del proyecto constitucionalista. Es una perspectiva crítica del lenguaje de la constitucionalización, pues no existe aquí un «ansia» o «adicción» a la utilización del lenguaje constitucional sin considerar las condiciones específicas del ámbito internacional (un constitucionalismo que crea jerarquías donde no son evidentes o busca unificar aquellos aspectos donde la diversidad produce ansiedad por la falta de orden) (Schwöbel, 2011, p. 147). Por el contrario, se reconoce la diversidad y especificidad de la esfera internacional y por ello es crítico, en el sentido de poner de relieve las circunstancias que hacen complejo el desarrollo de este paradigma a nivel internacional, pero sin renunciar a esta posibilidad (Peters, 2010, p. 261). A diferencia del discurso descriptivo, no se utiliza el lenguaje constitucional para dotar de una falsa legitimidad al Derecho internacional. Por el contrario, este discurso inicia un debate productivo y constructivo. Se parte de la base de que el ámbito internacional no posee una Constitución completa en el sentido más profundo y legítimo, por ello el proyecto del constitucionalismo cosmopolita ofrece respuestas para sortear las "lagunas" del discurso de la constitucionalización. En este sentido, el potencial crítico se manifiesta en el esfuerzo por identificar tendencias constitucionalistas, pero por sobre todo anticonstitucionalistas, con el objeto de proponer remedios a los déficits (Peters, 2010, pp. 246-252).

En un segundo sentido, el proyecto es crítico por el carácter eminentemente crítico del lenguaje constitucionalista. Éste es un lenguaje que exige someter a revisión continuamente los argumentos para sostener la autoridad legítima y, por ello, no mantiene un compromiso necesario con el status quo ya que ofrece un lenguaje para la crítica también desde una perspectiva interna (Ferrajoli, 2014, pp. 83-90). Por ello el lenguaje constitucionalista es una herramienta adecuada para realizar una crítica a las estructuras del Derecho internacional que se sustentan en la dominación y que exigen ser reconfiguradas en clave de autoridad legítima (Kumm, 2016).

Además de la dimensión constitucionalista a la que nos hemos referido, los vínculos que esta aproximación tiene con el cosmopolitismo hacen también de este discurso una aproximación fuertemente normativa. Es una mirada que tiene una pretensión de ser universal, al tener la humanidad y sus intereses comunes como objeto último de referencia (Peters, 2009a, p. 155; Bryde, 2006, p. 107), y es también es una reacción «a la experiencia universal de dominación de humanos sobre otros humanos» (Peters, 2010, p. 11). A diferencia de otro tipo de discursos normativos (como el constitucionalismo global orgánico) ${ }^{22}$, el constitucionalismo cosmopolita tiene una dimensión axiológica que es más intensa que la mera afirmación de la regulación de las relaciones internacionales. No se trata sólo de juridificación, sino de constitucionalización para la efectiva garantía universal de los derechos humanos.

\footnotetext{
22 El constitucionalismo global orgánico se presenta como un «universal negativo». En este sentido, el constitucionalismo global orgánico se presenta únicamente como «espacio» disponible para hablar, donde los diversos intereses pueden ser representados. Por ello se sostiene que se debe abandonar la idea presente en el constitucionalismo cosmopolita referida a la existencia de un catálogo de derechos y debe centrarse el discurso en la disputa de los intereses en juego (Schwöbel, 2011, p. 185).
} 


\subsubsection{Fundamentos conceptuales y empíricos}

Otro aspecto común de esta perspectiva, es su vocación por buscar motivaciones conceptuales y empíricas para justificar un constitucionalismo cosmopolita. Siguiendo la línea marcada por Kant (en "Hacia la paz perpetua»), quien buscó tanto razones pragmáticas (vinculadas a las tendencias que evidencian un tránsito hacia el cosmopolitismo), como motivos vinculados a la razón (Arcos, 2004, p. 17), esta aproximación desarrolla una comprensión del constitucionalismo cosmopolita realizando conexiones entre estas dos perspectivas ${ }^{23}$. Como se ha resaltado, se trata de posiciones prescriptivas, que no se limitan a describir o sistematizar las normas vigentes, sino que se proponen fundamentalmente sugerir criterios referidos a la legitimidad. Pero a la vez, este tipo de propuestas tampoco se derivan tan sólo de consideraciones estrictamente conceptuales, sino que también responden a condiciones socio-económicas del mundo contemporáneo, «el cosmopolitismo puede entenderse ciertamente como un programa normativo inherente a los presupuestos ilustrados de la modernidad. La adecuación normativa no es, sin embargo, el único punto de vista para evaluar el proyecto cosmopolita. No es sólo un programa normativo y un implícito diagnóstico de la época, sino también un programa práctico» (Velasco, 2013, p. 180).

Sobre el apoyo en argumentos empíricos, es relevante para el discurso del constitucionalismo cosmopolita el estudio de los procesos de constitucionalización que realiza la aproximación descriptiva. Si consideramos la legalidad internacional como un hecho dado, la reconstrucción en clave constitucionalista no es un artefacto, sino un ejercicio hermenéutico basado en circunstancias existentes en el plano internacional (Peters \& Armigeon, 2009, p. 385). En este sentido, para esta aproximación no hay una Constitución propiamente tal, sino una «Constitución embrionaria» (Ferrajoli, 2011a, p. 475; Habermas, 2006, p. 157), en el sentido de que existen un conjunto de reglas y principios contenidos en diversos textos internacionales, que cumplen funciones constitucionales.

Desde la perspectiva conceptual se sostiene que existe una conexión entre constitucionalismo y cosmopolitismo, desde tres perspectivas: (3.2.2.1) vocación expansiva del constitucionalismo; (3.2.2.2) carácter histórico del constitucionalismo y; (3.2.2.3) giro cosmopolita de la legitimidad constitucional.

\subsubsection{Vocación expansiva del constitucionalismo}

Desde la perspectiva conceptual, se sostiene que el constitucionalismo y el cosmopolitismo se encuentran conceptualmente en torno a la idea de la vocación expansiva del constitucionalismo (Ansuátegui, 2008). Esta vocación se da por el carácter expansivo de los derechos y su pretensión de universalidad. La tesis que se encuentra detrás de esto es que «la paulatina consecución de las exigencias de los derechos implica necesariamente una transformación de los marcos históricos y políticos en los que se han desarrollado los mismos» (p. 74). Para sostener la vocación expansiva del constitucionalismo y, por tanto, su conexión conceptual con el cosmopolitismo se utilizan tres argumentos: i) la eficacia, ii) perdurabilidad y, iii) coherencia del proyecto del constitucionalismo. Si el proyecto del constitucionalismo de los derechos, basado en la pretensión de universalidad de los mismos pretende ser eficaz, coherente y perdurable en el tiempo, debe ser un proyecto cosmopolita.

\footnotetext{
23 Siguiendo a Diggelman y Altwicker, en su clasificación de las estrategias de justificación del constitucionalismo global, estaríamos frente a aquellas estrategias que ellos denominan «éticopragmáticas» (Diggelmann \& Altwicker, 2008, p. 639).
} 
En relación a la eficacia, se sostiene que si los derechos tienen vocación de universalidad y el constitucionalismo es un proyecto destinado a limitar el poder para garantizar los derechos, su ideología debe trascender los márgenes del Estadonación. Para que la universalidad de los derechos sea eficaz la lógica del constitucionalismo debe expandirse. Se puede arribar a esta conclusión constatando que los derechos humanos pueden ser vulnerados por otros tipos de poderes (además del estatal) y que hay ámbitos de su garantía que no pueden ser satisfechos solo por el Estado-nación. La justificación de la propensión cosmopolita del constitucionalismo basada en la eficacia del proyecto constitucionalista puede ser caracterizada como una justificación «pesimista» (Ansuátegui, 2016, p. 18), en el sentido en que se concentra en las deficiencias del constitucionalismo estatal. O bien, también puede plantearse como una estrategia «compensatoria». Expandir el constitucionalismo permitiría compensar aquellos aspectos que el constitucionalismo doméstico no podría desarrollar de manera eficaz (Peters, 2010).

En un sentido similar, puede ubicarse aquella conexión basada en la necesidad de perdurabilidad del proyecto del constitucionalismo. Si el constitucionalismo aspira a ser un proyecto perdurable en el tiempo, debe adaptarse a las condiciones históricas que van moldeando su evolución para cumplir su vocación de limitación al poder. En el contexto de la globalización, conceptos como los de soberanía y ciudadanía asociados al Estado-nación se transforman en condicionantes que limitan la esfera de garantía de los derechos y justifican un control limitado del poder circunscrito al ámbito nacional (Brito, 2005, p. 115). Además, la progresiva aparición de otros poderes con capacidad regulativa y esferas de normatividad desarrolladas en el ámbito privado supranacional, van desarrollando un «vacío de derecho público» (Ferrajoli, 2005, p. 41), que exigen una expansión del constitucionalismo.

Finalmente, en relación a la coherencia del proyecto del constitucionalismo, se apuntan razones que vinculan conceptualmente el constitucionalismo y cosmopolitismo en relación a su fundamentación. Se debe recordar que tanto el constitucionalismo como el cosmopolitismo comparten la fundamentación de las obligaciones en la igual consideración y respeto por todos los seres humanos (en el caso del cosmopolitismo moral para justificar obligaciones morales y en el caso del constitucionalismo para justificar la acción legítima del poder). En este sentido, comparten en su fundamentación el meta-principio de la autonomía. Como señala Held, esta meta-principio es la base del proyecto cosmopolita y lo es también de la estructura profunda del constitucionalismo moderno (Held, 2012, p. 87). En este sentido, un constitucionalismo coherente con su fundamentación, aspira a ser cosmopolita. Como apunta Kumm, «cualquier concepción de constitucionalismo nacional que contiene la idea central de personas libres e iguales que se autodeterminan colectivamente está internamente conectada con una concepción cosmopolita del constitucionalismo» (Kumm, 2009, p.315).

Las consecuencias prácticas de la coherencia ponen de relieve necesidad de superar las aporías internas del constitucionalismo, como son los conceptos de soberanía y ciudadanía (Ferrajoli, 2010, p. 32; Habermas, 2000, p. 137). La tensión se da porque pese a que los derechos se han configurado teóricamente en términos universales, las condiciones para su realización y garantía se han desarrollado con criterios particularistas basados en criterios de pertenencia al Estado-nación. Frente a esta disyuntiva, las propuestas cosmopolitas plantean la necesidad de considerar a la humanidad como referente moral básico, cuestionando los criterios de exclusión basados, por ejemplo, en la nacionalidad. En este sentido, la exigencia de coherencia demanda revisar y reconfigurar estos conceptos en clave cosmopolita (Benhabib, 2005). 


\subsubsection{Vocación histórica del constitucionalismo}

Desde una perspectiva histórica, se sostiene que el constitucionalismo tiene una conexión con el cosmopolitismo en dos sentidos diferentes: (i) por la recuperación de la vocación histórica del constitucionalismo, que implica su conexión con el cosmopolitismo y, (ii) por el carácter histórico del constitucionalismo como proyecto en relación a los derechos.

Por una parte, es posible sostener que una comprensión cosmopolita del constitucionalismo en perspectiva contemporánea permite recuperar su sentido histórico en relación a los compromisos que inspiraron las revoluciones americana y francesa (Kumm, 2013, p. 611; Kumm, 2009, p. 315). En efecto, el constitucionalismo estatista (que identifica el constitucionalismo con el Estado-nación) mal interpreta la tradición constitucionalista, pues no considera que la perspectiva cosmopolita es inherente a la idea de autogobierno entre libres e iguales (Kumm, 2009, p.626). Para la tradición del S.XVIII la idea de poder constituyente asociada al concepto «We the people» es normativa y justificatoria, no sociológica o explicativa (Kumm, 2016, pp. 697-711).

En un sentido similar, Benhabib nos advierte que ha existido en relación al vocablo soberanía, una confusión entre soberanía estatal y soberanía popular (Benhabib, 2016, pp. 134-137) ${ }^{24}$. Cuando se identifica a los tratados internacionales sobre derechos humanos o la actuación de los organismos supranacionales de derechos humanos como una amenaza a la soberanía, lo que se hace es identificar soberanía popular con soberanía estatal. Sin embargo, si comprendemos a la soberanía como soberanía popular (es decir, aquella que reside en el pueblo donde el pueblo es sujeto y objeto de la ley), podemos advertir que la actuación de estos organismos puede reforzarla en la medida que tenga un sentido de inclusión para aquellos que no tienen voz y, en ese sentido, también es posible sostener que el constitucionalismo tiene una vocación cosmopolita.

Por ello, para esta aproximación es posible sostener que si el sentido histórico del constitucionalismo ha sido evitar la dominación bajo el establecimiento de autoridad legítima, este sentido requiere la incorporación del cosmopolitismo. Lo que se requiere, en este sentido, sería innovación conceptual para recuperar la idea de «voluntad común» en tiempos actuales, lo que se vería facilitado por la unión entre constitucionalismo y cosmopolitismo.

Desde la perspectiva histórica, también es posible sostener que el punto de encuentro entre cosmopolitismo y constitucionalismo se da por el carácter histórico que se ha destacado tanto del constitucionalismo (Fioravanti, 2014) como de los derechos (Peces-Barba, 1986). Este carácter ha supuesto que el constitucionalismo basado en derechos vaya expandiendo sus dimensiones (territoriales y materiales) para cumplir con sus objetivos y, en el caso de los derechos, se ha vinculado con diferentes procesos vinculados con el cosmopolitismo (como es la generalización e internacionalización de los derechos). Es en esta expansión que encuentran conexión histórica el constitucionalismo y el cosmopolitismo en el contexto de la llamada crisis del modelo de la paz de Westfalia, que se traduce en la pérdida de protagonismo de los Estados como actores exclusivos de la esfera internacional y como entes autónomos e independientes para la producción de normas. Es a partir del diseño institucional que se da a partir de la postguerra, caracterizado por la utilización de ciertas estructuras del constitucionalismo (como la garantía jurisdiccional de los

\footnotetext{
${ }^{24}$ Habermas también nos alerta de un «malentendido colectivista» de la soberanía que ha provocado una confusión que asocia soberanía a Estado (Habermas, 2012b, p. 50).
} 
derechos), que nacen mecanismos de control y normas que trascienden al Estado y lo limitan. El desarrollo de normas de Derecho internacional de los derechos humanos es central en este proceso. La normativa internacional se complejiza y, por tanto, ya no se trata solo de justificar una legalidad internacional, sino una legalidad cosmopolita basada en derechos universales (García Pascual, 2015, p. 153).

\subsubsection{Giro cosmopolita de la legitimidad constitucional}

Finalmente, se sostiene que existe una conexión entre constitucionalismo y cosmopolitismo en el sentido de que la legitimidad del constitucionalismo tradicional ha tomado un giro cosmopolita en la medida en que ahora la legitimidad constitucional nacional también depende en cómo el constitucionalismo estatal se integra y relaciona con la gran esfera jurídico-político mundial (Kumm, 2013, p. 612; Held, 2012, p. 30). Conforme a esta perspectiva, los estándares de legitimidad constitucional se derivan por una concepción integrativa del Derecho público que supera la división nacionalinternacional y es, por tanto, cosmopolita o, en palabras de Held, la soberanía es vista como «un conjunto de entornos interconectados de autoridad pública, formados y delimitados por un marco cosmopolita global» (Held, 2012, p. 30).

Esta afirmación se sustenta en las características del modelo de legitimidad constitucional. Si establecemos que en la «visión estándar» de la legitimidad constitucional el punto de partida es la necesidad de establecer relaciones justas entre libres e iguales y que, considerando el problema de la motivación y epistémico que subyace a los desacuerdos razonables en asuntos de justicia (Kumm, 2013, p. 615), se requiere un modelo de autoridad legítima que por medio de procedimientos imparciales y participativos permita arribar a decisiones justas, no hay razones válidas para entender que este tipo de razonamiento sólo valga para determinados tipos de externalidades, salvo que estemos dispuestos a entender que la libertad y la igualdad no sean la base del modelo de legitimidad constitucional.

La argumentación que subyace bajo esta concepción es que existen decisiones que aunque en el modelo tradicional de legitimidad se encuentren justificadas, pueden generar externalidades negativas para otros que envuelven necesidades de justificación ${ }^{25}$. Salvo que estemos dispuestos a asumir un modelo de relación de dominación (es decir, legitimidad que funciona como dominación) (Kumm, 2013, p. 617), estas externalidades negativas deben ser incorporadas y, por tanto, la legitimidad constitucional debe asumir un giro cosmopolita que considere que la legitimidad constitucional depende, en parte, en cómo las constituciones nacionales se integran y relacionan con la esfera político-jurídico global (Kumm, 2013, p. 625). Desde esta perspectiva, no hay cuestiones en las que un sistema constitucional (por más democrático que sea internamente) pueda exigir ejercicio de autoridad constitucional legítima si sus decisiones afectan a otros que no han sido considerados en el proceso de decisión (Kumm, 2013, p. 617).

El giro cosmopolita de la legitimidad constitucional implica, por tanto, considerar que en cuestiones de justicia cada Estado está bajo la obligación de estar sujeto, apoyar y ayudar al futuro desarrollo de un sistema constitucional de Derecho

\footnotetext{
${ }^{25}$ Evidentemente en esta argumentación subyace una visión cosmopolita de la relevancia moral del otro, como explica Benhabib: «cada persona y todo agente moral que tiene intereses y a quienes mis acciones y las consecuencias de mis acciones puede impactar y afectar de una manera u otra, es potencialmente participante en la conversación moral conmigo: tengo la obligación moral de justificar mis acciones con razones ante este individuo o los representantes de este ser» (Benhabib, 2005, p. 15).En este sentido, esta perspectiva vuelve a coincidir en la conexión del conexión entre constitucionalismo y cosmopolitismo en relación a su fundamentación. La perspectiva de la «justificación» es desarrollada especialmente por (Forst, 2014).
} 
Internacional que esté preparado desde la perspectiva del discurso de la autoridad legítima, para enfrentar estos problemas (Kumm, 2013, p. 617). Por ello, la legitimidad con giro cosmopolita implica una mirada conjunta del «We the people» que incorpora a la comunidad internacional (Kumm, 2016, p. 709).

\subsubsection{Importancia de los derechos, la democracia y Estado de Derecho ${ }^{26}$}

El constitucionalismo cosmopolita está densamente cargado de prescripciones, que se caracterizan por el rol central que ocupan los derechos humanos, la democracia y el Estado de Derecho en la motivación del proyecto, en lo que se ha caracterizado como la «trinidad del constitucionalismo global» (Kumm, Lang, Tully, \& Wiener, 2014). Aunque el concepto y fundamento de los derechos humanos puedan cambiar, las concepciones de la democracia, o bien la institucionalización de la relación entre estos tres elementos ${ }^{27}$, lo cierto es que la conquista de estos objetivos a nivel global se transforma en la meta del constitucionalismo cosmopolita y a la vez, fundamenta la comprensión de la legitimidad en este modelo.

Esto implica que en esta propuesta hay una reflexión en la que Estado de Derecho, democracia y derechos humanos tienen una conexión (es decir, no se trata de elementos que puedan analizarse aisladamente: Ansuátegui, 2013). Sin embargo, no se trata de la misma conexión que se sostiene respecto del modelo del Estado Constitucional, porque se adicionan o modifican elementos en relación a la comprensión de legitimidad del modelo ${ }^{28}$. A grandes rasgos, es posible sostener que la relación se daría de la siguiente manera: en relación con los derechos humanos, la dimensión cosmopolita del proyecto impregna la necesidad de buscar su satisfacción universal. Los derechos operan como meta a alcanzar, y a la vez, como requisito de legitimidad de las decisiones (internacionales e internas). La democracia, por su parte, no sólo se transforma en un objetivo hacia el interior de los Estados (con la novedad adicional de que la perspectiva cosmopolita agrega exigencias a la legitimidad del «modelo tradicional»), sino también forma parte de la instauración de una autoridad legítima a nivel internacional y; finalmente, la dimensión del Estado de Derecho Constitucional resalta que la estrategia de limitación al poder para lograr estos objetivos, es constitucional. Una novedad respecto del modelo que podríamos llamar «radicional», es que la relación con el poder aquí no solo es con el poder público, sino también con cualquier poder que tenga potencial de afectación de los derechos, incluyendo el poder privado. Una de los desafíos que tiene el modelo cosmopolita es articular estrategias jurídicas capaces de identificar y limitar esos poderes.

\footnotetext{
${ }^{26}$ La expresión utilizada por la literatura del constitucionalismo global es «rule of law». El significado de rule of law, dependiendo del contexto, puede ser entendido como «imperio de la ley» o «Estado de Derecho». En este caso se ha escogido traducir el sentido de la literatura angloparlante con el vocablo «Estado de Derecho» por el contenido sustantivo que se asocia al rule of law en el debate sobre constitucionalismo global. Véase, en general, sobre la relación y diferencias entre ambos conceptos (Ansuátegui, 2013 y Craig, 1997). Existen otras aproximaciones sobre aplicación del rule of law a nivel global, pero desde una comprensión que sostiene que es posible separar conceptualmente Estado de Derecho, democracia y derechos fundamentales y, por tanto, es posible plantear un proyecto global de Estado de Derecho cuya estrategia no sea constitucional, véase, por ejemplo: (Palombella, 2012; 2014). 27 Sobre las diferencias respecto a estos elementos en las diferentes propuestas del constitucionalismo cosmopolita, véase el análisis comparativo de las propuestas de Habermas y Ferrajoli que se realizó en (Núñez, 2017).

${ }^{28}$ En el caso de Habermas se propone una democracia desagregada en múltiples niveles con diferentes cadenas de legitimación (Habermas, 2008; 2016). Para Ferrajoli el desafío consiste en establecer diseños institucionales que logren separar funcionalmente la garantía y gobierno realizando modificaciones relevantes a la estructura de Naciones Unidas y otros organismos internacionales (Ferrajoli, 2011a; Ferrajoli, 2018). Para Kumm se trata de establecer un modelo complejo de legitimidad con criterios sustantivos y procedimentales (Kumm, 2009). Para Peters, se trata de cambiar los conceptos de ciudadanía y representación democrática transnacional (Peters, 2009b).
} 
Por esta razón es que se sostiene también que el constitucionalismo cosmopolita es transformador respecto del constitucionalismo en su totalidad, porque aporta elementos para una reflexión más amplia de cómo concebir el constitucionalismo no sólo en el ámbito internacional, sino que en general se cuestiona la forma en que se ha construido los parámetros de legitimidad y el concepto de poder en el constitucionalismo «estatal».

\subsubsection{Heredero de una tradición en la historia de las ideas políticas}

Finalmente, la última característica relevante para identificar al discurso del constitucionalismo cosmopolita son las influencias de las que es heredero en la historia de las ideas políticas. Una de las aproximaciones doctrinarias que distingue el discurso del constitucionalismo global entre aproximaciones normativas ${ }^{29}$, funcionalistas y pluralistas, destaca que éstas no se diferencian en términos filosóficos, sino más bien en términos pragmáticos (Wiener, Lang, Tully, Maduro, \& Kumm, 2012, p. 6). Sin embargo, una de las ventajas del enfoque propuesto es que permite poner de relieve que sí existen diferencias en las diferentes aproximaciones normativas y es que precisamente el constitucionalismo cosmopolita es heredero de una tradición larga en la historia de las ideas políticas vinculada a los ideales de la modernidad y el pacifismo jurídico (a diferencia del constitucionalismo global orgánico que tiene influencias posmodernas) y, por otra parte, a diferencia de la perspectiva descriptiva de la constitucionalización, no sólo se ancla en motivaciones empíricas justificadas por la globalización, sino que es un producto complejo que combina estas dimensiones junto con un anclaje conceptual anterior.

Si situamos al pacifismo jurídico como una tradición cuyos principales elementos inician con Kant y cobran renovada trascendencia en la literatura del S. XX (Kelsen, Bobbio), su tópico común ha sido relevar el rol del Derecho como mecanismo para alcanzar la paz y su necesario desarrollo más allá de los márgenes estatales ${ }^{30}$. En este sentido, el discurso del constitucionalismo cosmopolita es heredero de esta tradición respecto de las cual se erige como continuador (no solo porque sus principales representantes hacen alusión a estos antecedentes, sino por sobre todo porque estas ideas se encuentran en la base de la argumentación actual), y asume el relevo de una construcción teórica que en la actualidad se enfrenta a desafíos complejos y que moldean las especificidades de la respuesta contemporánea. Si Kant inicia este camino y el pacifismo kelseniano lo continúa, el constitucionalismo cosmopolita presente en autores como Habermas o Ferrajoli podría ser considerada la «tercera generación» de esta tradición de filosofía político-jurídica.

Las diferencias que se marcan con los planteamientos precedentes vienen dadas por el contexto histórico en que se empiezan a desarrollar estas ideas y los desafíos diversos y complejos que debe enfrentar un discurso de este tipo en tiempos de globalización. Por ejemplo, uno de los elementos diferenciadores de esta nueva etapa es caracterizado por Koskenniemi en base a tres conceptos: «desformalización», «fragmentación»e «imperio» (Koskenniemi, 2006). La desformalización se referiría a la proliferación de normativa emanada a partir de

\footnotetext{
${ }^{29}$ Por ejemplo, un ejercicio de análisis interesante en relación a la historia de las ideas en esta materia y sus respectivos relatos filosóficos se hace en el libro "Handbook of global constitutionalism», donde se analiza la influencia del cosmopolitismo («Cosmopolitanism and Global Constitutionalism» de Garrett Wallace Brown), el liberalismo («Liberal Theory» de lain Ferguson), el constructivismo («Constructivism» de Jan Wilknes), el realismo («Realist perspectives on Global Constitutionalism» de Oliver Jütersonke), y la teoría crítica («Critical Theory» de Gavin W. Anderson), véase: (Lang \& Wiener, 2017).

${ }^{30}$ Esta construcción teórica asume algunos de los siguientes postulados: 1) relevancia del Derecho como mecanismo para alcanzar la paz; 2) cuestionamiento de la idea de soberanía; 3) relativización de la importancia del Estado en relación al Derecho y; 4) relevancia de la dimensión jurisdiccional y la centralización del poder. Sobre la tradición del pacifismo jurídico, véase: (García Sáez, 2014).
} 
directrices de comités de expertos, que se presentan como soluciones funcionales; la fragmentación es el fenómeno de división de la normativa internacional en diferentes regímenes diferenciados (como derechos humanos, comercio internacional o medio ambiente); y la característica «imperial», haría referencia a la aparición de patrones de dominación deliberadamente intencionados para avanzar hacia los objetivos de un solo actor dominante. Estas características generan, por ejemplo, que en el caso del discurso del constitucionalismo cosmopolita resulte central la generación de estrategias de coordinación entre sistemas jurídicos, y que, por tanto, se presente como un discurso que busque superar los problemas de fragmentación y se cuestione la idea de monismo clásica del pacifismo ${ }^{31}$.

Junto con estas características generales del panorama jurídico internacional, en relación con el panorama político, si para el pacifismo del S. XX resultaron determinantes las guerras mundiales, para el constitucionalismo cosmopolita del S. XXI desde la perspectiva internacional resulta determinante el unilateralismo de EE.UU, las intervenciones humanitarias y la relativización de los derechos humanos asociada a estos fenómenos y al terrorismo internacional (Habermas, 2006, pp. 113115).En el ámbito interno, el panorama político reciente ha sido el de la crisis de la democracia constitucional (Ferrajoli, 2018, p. 16; Ferrajoli, 2005), lo que ha incidido en que para este discurso sean relevantes las críticas dirigidas al constitucionalismo como paradigma y la erosión de la democracia constitucional generada por la globalización. Esto ha significado para el constitucionalismo cosmopolita tanto un desafío, como una oportunidad. Un desafío en cuanto debe plantearse fundamentar los principios de la democracia constitucional (aspectos que hasta antes de la crisis no eran cuestionados) y, por otra parte, se presenta como una oportunidad en la medida en que el constitucionalismo cosmopolita logra presentarse como una de las soluciones a esta crisis.

Todos los elementos que hemos señalado inciden en que los aspectos comunes que se han identificado con la tradición pacifista adquieran algunos contornos particulares.

Por ejemplo, en relación con rol del Derecho y el objetivo del proyecto, la centralidad que adquieren los derechos humanos en el modelo del constitucionalismo de postguerra hace que el proyecto del constitucionalismo cosmopolita, a diferencia de sus predecesores, tenga un objetivo más amplio que la garantía de la paz. En efecto, en base a una consideración de que la guerra tiene factores complejos que la explican y sustentan, el constitucionalismo cosmopolita apunta no solo a la prevención de la violencia, sino a los presupuestos reales de una vida en común sin tensiones. Si bien en los antecedentes del debate el tema de la guerra se presentaba como la única preocupación de los cosmopolitas jurídicos, en las propuestas contemporáneas el análisis es de mayor complejidad, incorporando dimensiones económicas y sociales, no solamente jurídicas. La «paz por medio del Derecho» ha cambiado de significado y en la actualidad ya no significa ausencia de guerra, sino fundamentalmente garantía efectiva de los derechos humanos (García Pascual, 2015, pp. 189-190). Esto se puede apreciar, por ejemplo, en las propuestas de Ferrajoli referidas a un constitucionalismo de los derechos sociales o de los bienes comunes de la humanidad o a la importancia que Habermas da a la igualdad de espacios de

\footnotetext{
${ }^{31}$ Aunque para esta propuesta es relevante la problemática sobre la unidad del Derecho y la coordinación de ordenamientos jurídicos, no existe una visión unificada de cómo abordarse esta cuestión en las diferentes aproximaciones del constitucionalismo cosmopolita. Mientras hay autores que apuestan por el monismo (como Habermas), otros optan por el pluralismo como la mejor forma de abordar las relaciones entre los diversos niveles del Derecho (como Ferrajoli y Kumm). En este sentido, uno de los principales desafíos de la propuesta radica en sostener un discurso que, desde la teoría del Derecho, sea coherente y lo suficientemente complejo como para abordar los desafíos del modelo cosmopolita.
} 
participación democrática en la deliberación transnacional. En todo caso, cabe señalar que el vocablo "Derecho» adquiere connotaciones particulares, ya que no estamos solo frente a la juridificación de las relaciones internacionales, la caracterización constitucionalista añade un elemento vinculado a una promesa de legitimidad vinculado con una idea de autoridad legítima, límite al poder y garantía de derechos.

Por otra parte, las condiciones del mundo contemporáneo y, en particular las exigencias derivadas de la realidad, ya sea por la omisión que los proyectos anteriores hacían de la diversidad cultural ${ }^{32}$ o por la emergencia de un discurso de relativización de los derechos humanos, hacen que este proyecto tenga que preocuparse también por fundamentar los derechos humanos desde una perspectiva compatible con su pretensión cosmopolita.

En relación con el cuestionamiento de la soberanía, en el caso del constitucionalismo cosmopolita cobra una importancia vital la idea de desmitificación del Estado (García Sáez, 2017, p. 161). Esta idea que para los pacifistas era necesaria para sostener la validez del Derecho internacional, en el caso del constitucionalismo cosmopolita es un argumento que se profundiza con el objetivo de sostener la posibilidad teórica de hablar de Constitución más allá del Estado. En este sentido, la desmitificación del Estado se transforma en desmitificación de la relación entre Constitución y Estado.

Finalmente, otro rasgo característico de este discurso en relación con la tradición que lo precede, es su vínculo con el poder. Una de las características que se manifiestan en el panorama contemporáneo, son las dificultades en la identificación del poder que se busca regular. Si la tarea de la federación kantiana y del pacifismo era compleja, la del constitucionalismo cosmopolita lo es aún más, en la medida en que ya no son solo los Estados los únicos actores con capacidad para afectar la autonomía de los individuos. Se ha producido una inversión de la jerarquía de los poderes hace que el poder económico se alce por encima incluso del poder político (Ferrajoli, 2018, p. 19). En este sentido, el constitucionalismo cosmopolita debe alejarse la máxima de Kelsen que sostenía que «no es el capitalismo -y esto se aplica a cualquier otro sistema o situación económicos- sino la organización política anárquica del mundo la enfermedad esencial de nuestra civilización» (Kelsen, 2008, p. 50) y debe aventurarse también a incorporar a poderes «salvajes» y difusos en el modelo de coordinación con el Derecho. Una de las preocupaciones centrales del constitucionalismo cosmopolita es la regulación del poder (no solo político, sino también económico), para la garantía de los derechos humanos.

Aunque el escenario descrito sea complejo, también existen elementos presentes en la realidad y que favorecen este tipo de discurso y que, a diferencia del discurso kantiano o pacifista, actualizan las posibilidades del discurso cosmopolita en el contexto de la globalización. Estos rasgos están dados por el surgimiento de problemáticas globales comunes, tratados internacionales, organismos internacionales y supranacionales, diálogo entre tribunales internacionales, entre otros, lo que genera que los rasgos del mundo contemporáneo puedan interpretarse tanto en clave de obstáculo como en clave de posibilidad. La globalización forma un contexto en el que no aparecen como insuperables las resistencias contra un constitucionalismo cosmopolita (Habermas, 2006, p. 167). Estos rasgos hacen que, a diferencia del utopismo que caracterizó el proyecto kantiano y pacifista del S. XX, un

\footnotetext{
32 Kelsen, por ejemplo, en el contexto de su discurso pacifista, aludía a la necesidad de una evolución larga y lenta que igualara las diferencias culturales del mundo, lo que se lograría mediante una labor política y educativa (Kelsen, 2008, p. 46).
} 
elemento central para el discurso cosmopolita es la normatividad que brinda el sistema internacional. El desarrollo del Derecho internacional de los derechos humanos, el Derecho penal internacional y el Derecho internacional humanitario dotan de una base jurídica a esta aspiración. Como señala García Pascual, «en cierta medida la comunidad internacional que algunos filósofos de la moral buscan y quieren justificar para sobre la misma construir un mundo más justo, ya existe para los juristas. Es la comunidad, todavía frágil por supuesto, que gobierna el Derecho internacional» (García Pascual, 2017, p. 126).

\section{Conclusiones}

El lenguaje constitucionalista en la esfera internacional ha sido utilizado con diversas nomenclaturas y significados. Se ha sostenido que dentro de este es posible diferenciar entre aproximaciones descriptivas y normativas. El constitucionalismo cosmopolita, aunque contenga elementos descriptivos, se erige como una alternativa a los problemas de las perspectivas descriptivas y es una aproximación normativa que engloba diferentes propuestas referidas a la transformación del paradigma del constitucionalismo en el contexto de la globalización y que busca la aplicación de los principios e instituciones del constitucionalismo a nivel global (democracia, derechos humanos y rule of law).

El objetivo del proyecto es establecer las condiciones para el goce y ejercicio efectivo de los derechos humanos en todo el mundo, fijar límites al poder (que puede ser un poder estatal, supranacional o privado) y condiciones para su ejercicio legítimo considerando las particularidades del escenario postwestfaliano. Pese a que en este discurso hay diferentes enfoques, se destacaron sus rasgos distintivos y comunes. Es un proyecto transformador y crítico, porque la incorporación de la dimensión cosmopolita transforma la comprensión del constitucionalismo tradicional, proponiendo nuevos criterios para la creación y aplicación del Derecho y el establecimiento de la autoridad legítima en términos cosmopolitas. Desde la perspectiva de su fundamentación, se ha destacado que argumentativamente se sustenta en fundamentos pragmáticos (anclados en la realidad de la normativa internacional) y conceptuales (mediante conexiones conceptuales que se hacen entre constitucionalismo y cosmopolitismo). Estas conexiones conceptuales se vinculan a la idea de la vocación expansiva del constitucionalismo, el carácter histórico del constitucionalismo y el giro cosmopolita que ha adquirido la legitimidad constitucional. Asimismo, como característica del proyecto, se resaltó que es un concepto heredero de una larga tradición en la historia de las ideas políticas (pacifismo jurídico), pero con ciertos rasgos particulares vinculados a su objetivo como proyecto y a las características del panorama internacional contemporáneo.

Estos rasgos comunes permiten calificar al constitucionalismo cosmopolita como un discurso específico que pretende plantearse como una alternativa a la comprensión estatal del constitucionalismo, con antecedentes, características y fundamentos que le son propios.

\section{Bibliografía}

Ansuátegui, F. J. (2008). La dimensión expansiva del constitucionalismo. retos y exigencias. En VV.AA. Entre la ética, la política y el derecho: estudios en homenaje al profesor Gregorio Peces-Barba. Vol. II. (pp. 73-104). Madrid: Dykinson e Instituto de Derechos Humanos Bartolomé de las Casas, Universidad Carlos III de Madrid. 
Ansuátegui, F. J. (2013). Razón y voluntad en el Estado de Derecho: Un enfoque filosófico jurídico. Madrid: Dykinson e Instituto de Derechos Humanos Bartolomé de las Casas, Universidad Carlos III de Madrid.

Ansuátegui, F. J. (2016). La propensione cosmopolita del costituzionalismo. Diritto \& Questioni Pubbliche, 16 (1), pp.12-27.

Arcos, F. (2004). Una lectura del cosmopolitismo kantiano. Anuario de Filosofía del Derecho, (21), pp.13-38.

Arcos, F. (2009). La justicia más allá de las fronteras. Fundamentos y límites del cosmopolitismo. Valencia: Tirant Lo Blanch.

Atilgan, A. (2017). Global Constitutionalism: A Socio-Legal perspective. Berlín; Heidelberg: Springer.

Beck, U. (2005). La mirada cosmopolita o la guerra es la paz. Barcelona: Paidós.

Beitz, C. (2005). Cosmopolitanism and global justice. The Journal of Ethics 9 (1-2), pp. 11-27.

Benhabib, S. (2005). Los derechos de los otros: Extranjeros, residentes y ciudadanos. Barcelona: Gedisa.

Benhabib, S. (2016). The new sovereigntism and transnational law: legal utopianism, democratic scepticism and statist realism. Global Constitutionalism, 5(1), pp. 109144.

Bodansky, D. (2009). Is there an international environmental Constitution? Indiana Journal of Global Legal Studies, 16(2), pp. 565-584.

Bogdandy, A. v. (2006). Constitutionalism in international law: Comment on a proposal from Germany. Harvard International Law Journal, 47(1), pp. 223-242.

Brito, R. (2005). Constitucionalismo global. México: Porrúa, Universidad Nacional Autónoma de México.

Brock, G. y Brighouse, H. (Eds) (2005). The political philosophy of cosmopolitanism. Cambridge; New York: Cambridge University Press.

Brown, G. W. (2012). The constitutionalization of what? Global Constitutionalism, 1(2), pp.201-228.

Brown, G. W. (2013). Grounding cosmopolitanism: from Kant to the idea of a cosmopolitan Constitution. Edinburgh: Edinburgh University Press.

Brown, G. W (2016). Cosmopolitanism and global constitutionalism. Comunicación presentada en ECPR General Conference, Praga, 7-10 de septiembre de 2016, pp. 1-9.

Bryde, B.O (2005), International Democratic Constitutionalism. In R. St. J. MacDonald y D. Johnston (Eds.) Towards world constitutionalism. Issues in the legal ordering of the world community. Leiden: Martinus Nijhoff Publishers.

Carbonell, M. (Ed). (2009). Neoconstitucionalismo(s), 4ª ed. Madrid: Trotta.

CDI (2006), Fragmentation of International Law: Difficulties arising from the diversification and expansion of International Law. Report of the Study Group of the International Law Commission, April 13' 2006, http://legal.un.org/ilc/documentation/english/a_cn4_1682.pdf

Chernilo, D. (2015). Las relaciones entre nacionalismo y cosmopolitismo. Papers: Revista de Sociología, 100 (3), pp. 303-324.

Cortés, F. \& Piedrahita, F. (2011). De Westfalia a cosmópolis: Soberanía, ciudadanía, derechos humanos y justicia económica global. Bogotá: Siglo del Hombre Editores.

Craig, P. (1997). Formal and substantive conceptions of the rule of law: An analytical framework. Public Law, (3), pp. 467-487.

Comanducci, P. (2002), Formas de (neo) constitucionalismo: un análisis metateórico, Isonomía, pp. 89-112.

Comanducci, P. (2011). Constitucionalismo: problemas de definición y tipología, Doxa: Cuadernos de Filosofía del Derecho (34), pp. 95-100.

Delanty, G. (2012), The emerging field of cosmopolitan studies, In Routledge Handbook of cosmopolitan studies. New York: Routledge. 
Diggelmann, O., \& Altwicker, T. (2008). Is there something like a constitution of international law? Zeitschrift Für Ausländisches Öffentliches Recht Und Völkerrecht, 68, pp.623-650.

Dupuy, P. (1997). The Constitutional Dimension of the Charter of the United Nations Revisited, Max Planck Yearbook of United Nations Law Online, 1(1), pp.1-33.

Fariñas, M. J. (2000). De la globalización económica a la globalización del Derecho: Los nuevos escenarios jurídicos. Derechos y Libertades, 5(8), pp. 179-194.

Fassbender, B. (1998). The United Nations Charter as Constitution of the international community. Columbia Journal of Transnational Law, 36(3), pp. 529-619.

Fassbender, B. (2010). La protección de los derechos humanos como contenido central del bien común internacional. En A. Peters, M.J. Aznar \& I. Gutiérrez, La constitucionalización de la comunidad internacional (pp. 121-175), Valencia: Tirant lo Blanch.

Ferrajoli, L. (1998). Más allá de la soberanía y la ciudadanía: Un constitucionalismo global. Isonomía: Revista de teoría y filosofía del Derecho, (9), pp.173-184.

Ferrajoli, L. (2004). Razones jurídicas del pacifismo. Madrid: Editorial Trotta.

Ferrajoli, L. (2005). La crisis de la democracia en la era de la globalización. Anales de la Cátedra Francisco Suárez, (39), pp.37-51.

Ferrajoli, L. (2008). Democracia y garantismo. Madrid: Trotta.

Ferrajoli, L. (2010). Derechos y garantías: La ley del más débil ( $7^{\mathrm{a}}$ ed.). Madrid: Trotta.

Ferrajoli, L. (2011a). Principia luris: teoría del derecho y la democracia. Vol. II. Madrid: Trotta.

Ferrajoli, L. (2011b). Constitucionalismo principialista y constitucionalismo garantista. Doxa: Cuadernos de Filosofía del Derecho (34), pp. 15-54.

Ferrajoli, L. (2014). La democracia a través de los derechos: El constitucionalismo garantista como modelo teórico y como proyecto político. Madrid: Trotta.

Ferrajoli, L. (2018). Constitucionalismo más allá del Estado. Madrid: Trotta, 2018.

Ferrajoli, L. y Ruiz Manero, J. (2012). Dos modelos de constitucionalismo: una conversación. Madrid: Trotta.

Fioravanti, M. (2014). Constitucionalismo: Experiencias históricas y tendencias actuales. Madrid: Trotta.

Forst, R. (2014). Justificación y crítica. Perspectivas para una teoría crítica de la política. Buenos Aires: Katz.

García Sáez, J. A. (2014). El pacifismo jurídico en el siglo XX a través de las obras de Kelsen, Bobbio y Ferrajoli. En Ansuátegui, F. J.; Fernández, E., Peces-Barba, G. \& Rodríguez, J. M. (Eds.), Historia de los derechos fundamentales. Siglo $X X$. Tomo IV, Vol II. (pp. 651-685) Madrid: Dykinson e Instituto de Derechos Humanos "Bartolomé de las Casas", Universidad Carlos III de Madrid.

García Sáez, J. A. (2017). Kelsen versus Morgenthau: Paz, política y Derecho internacional. Madrid: Centro de Estudios Políticos y Constitucionales.

García Pascual, C. (2015). Norma mundi: La lucha por el derecho internacional. Madrid: Trotta.

García Pascual, C. (2017). Orden global justo y derecho internacional en transformación. Doxa: Cuadernos de Filosofía del Derecho, (39), pp. 121-126

Gutiérrez, I. (2010). De la constitución del Estado al Derecho Constitucional para la comunidad internacional. En A. Peters, M.J. Aznar \& I. Gutiérrez (Eds.), La constitucionalización de la comunidad internacional (pp. 15-92). Valencia: Tirant lo Blanch.

Häberle, P. (2013). Pluralismo y Constitución: Estudios de teoría constitucional de la sociedad abierta. Madrid: Tecnos.

Habermas, J. (1997). Kant's idea of perpetual peace with the benefit of two hundred years' hindsight. In J. Bohman, \& M. Lutz-Bachmann (Eds.), Perpetual peace: Essays on Kant's cosmopolitan ideal (pp. 113-153). London: The MIT Press.

Habermas, J. (2000). La inclusión del otro. Estudios de teoría política. Trad. J. C. Velasco y G. Vilar. Barcelona: Paidós. 
Habermas, J. (2006). El Occidente escindido: Pequeños escritos políticos X. Madrid: Trotta.

Habermas, J. (2008). The constitutionalization of international law and the legitimation problems of a constitution for world society. Constellations, 15(4), pp.444-455.

Habermas, J. (2009). ¡Ay Europa!: Pequeños escritos políticos XI. Madrid: Trotta.

Habermas, J. (2012a). The crisis of the European union in the light of a constitutionalization of international law. European Journal of International Law, 23(2), pp. 335-348.

Habermas, J. (2012). La Constitución de Europa. Madrid: Trotta.

Habermas, J. (2014). Plea for a constitutionalization of international law. Philosophy \& Social Criticism, 40(1), pp. 5-12.

Habermas, J. (2015). The lure of technocracy. Cambridge: Polity.

Habermas, J. (2016). ¿Es posible una constitución política para la sociedad mundial pluralista? Anales de la Cátedra Francisco Suárez, (50), pp. 303-315.

Held, D. (2012). Cosmopolitismo: Ideales y realidades. Madrid: Alianza Editorial.

Kadelbach, S., \& Kleinlein, T. (2007). International law -A Constitution for mankind? an attempt at a re-appraisal with an analysis of constitutional principles. German Yearbook of International Law, 50, pp. 303-348.

Kelsen, H. (2008). La paz por medio del Derecho ( $2^{\mathrm{a}}$ ed.). Madrid: Trotta.

Klabbers, J. (2009). Setting the scene. En A. Peters, G. Ulfstein \& J. Klabers (Eds.), The constitutionalization of international law (pp. 1-44). Oxford; New York: Oxford University Press.

Koskenniemi, M. (2005). From apology to utopia: The structure of international legal argument. Cambridge: Cambridge University Press.

Koskenniemi, M. (2006). Constitutionalism as mindset: Reflections on kantian themes about international law and globalization. Theoretical Inquiries in Law, 8(1), pp. 936.

Koskenniemi, M. (2010). El destino del Derecho Internacional Público: entre la técnica y la política. Revista de Derecho Público Universidad de los Andes, 24, pp. 3-31.

Kumm, M., Lang, A., Tully, J., \& Wiener, A. (2014). How large is the world of global constitutionalism? Global Constitutionalism, 3(1), pp. 1-8.

Kumm, M. (2004). The legitimacy of international law: A constitutionalist framework of analysis. European Journal of International Law, 15(5), pp. 907-932.

Kumm, M. (2009). The cosmopolitan turn in constitutionalism: On the relationship between constitutionalism in and beyond the state. En D. Dunoff, \& J. P. Trachtmann (Eds.), Ruling the world? constitutionalism, international law and global governance (pp. 258-324). Cambridge: Cambridge University Press.

Kumm, M. (2013). The cosmopolitan turn in constitutionalism: An integrated conception of public law. Indiana Journal of Global Legal Studies, 20(2), pp. 605628.

Kumm, M. (2016). Constituent power, boundaries and identity: On the justificatory depth of constitutionalism - A rejoinder to Neil Walker. International Journal of Constitutional Law, 14(4), pp. 914-924.

Lang, A., \& Wiener, A. (2017). A constitutionalizing global order: An introduction. En A. Lang, \& A. Wiener (Eds.), Handbook of global constitutionalism,pp. 1-20. Cheltenham: Elgar Publishing.

Loughlin, M. (2010). What is constitutionalization? En P. Dobner \& M. Loughlin (Eds.) The Twilight of Constitutionalism? (pp. 46-69). Oxford: Oxford University Press.

MacDonald, R., \& Johnston, D. M. (2005). Towards world constitutionalism: Issues in the legal ordering of the world community. Leiden; Boston: Martinus Nijhoff Publishers.

Mac Amhlaigh, C. (2016), Harmonising Global Constitutionalism, Global Constitutionalism, 5 (2), pp.173-206.

Mosler, $\mathrm{H}$. (1980). The international society as a legal community. The Netherlands: Sijthoof \& Noordhoff. 
Neves, M. (2013). Transconstitutionalism. Oxford: Hart Publishing.

Núñez, C. (2017). Constitucionalismo cosmopolita en debate. Tesina para obtener el grado de Máster en Estudios Avanzados en Derechos Humanos. Madrid: Universidad Carlos III de Madrid.

Palombella, G. (2012). Ė possibile una legalità globale? il rule of law e la governance del mondo. Bolonia: II Mulino.

Palombella, G. (2014). El Estado de Derecho allende el Estado: Fracasos, promesas y teoría. En A. Julios-Campuzano (Ed.), El horizonte constitucional. ciencia jurídica, derechos humanos y constitucionalismo cosmopolita (pp. 341-368). Madrid: Dykinson.

Peces-Barba, G. (1986). Sobre el puesto en la historia de los derechos fundamentales, Anuario de Derechos Humanos, (4), pp.219-258

Pernice, I. (2012) La dimensión global del constitucionalismo multinivel. Una respuesta global a los desafíos de la globalización. Documento de Trabajo № 61 . Madrid: CEU Ediciones.

Pérez de la Fuente, O. (2006). Algunas estrategias para la virtud cosmopolita, Derechos y Libertades, (15), pp. 65-100.

Peters, A., \& Armingeon, K. (2009). Introduction. Global constitutionalism from an interdisciplinary perspective. Indiana Journal of Global Legal Studies, 16(2), pp. 385-395.

Peters, A. (2009a). Membership in the global constitutional community. En J. Klabbers, A. Peters\&G. Ulfstein (Eds.), The Constitutionalization of International Law (pp. 153-262). Oxford: Oxford University Press.

Peters, A. (2009). Dual democracy. En J. Klabbers, A. Peters \& G. Ulfstein (Eds.), The Constitutionalization of International Law (pp. 263-352). Oxford: Oxford University Press.

Peters, A. (2010). Constitucionalismo compensatorio: Las funciones y el potencial de las normas y estructuras internacionales. En A. Peters, M.J Aznar \& I. Gutiérrez (Eds.), La constitucionalización de la comunidad internacional (1st ed., pp. 208262). Valencia: Tirant lo Blanch.

Peters, A. (2018). Los méritos del constitucionalismo global. Revista Derecho del Estado, (40), pp. 3-20.

Petersmann, E. (2013a). Global Constitutional Law? Why Cosmopolitan "Aggregate Public Goods" must be protected by cosmopolitan conceptions of international law. En M. C. Bassiouni, G. Joanna, P. Mengozzi (Eds). The Global Community yearbook of international law and jurisprudence: global trends: law, policy \& justice essays in honour of Professor Giuliana Ziccardi Capaldo. Oxford Scholarship online, dx.doi.org/10.1093/acprof:osobl/9780199332304.003.0025.

Petersmann, E. (2013b). Human rights require 'cosmopolitan constitutionalism' and cosmopolitan law for democratic governance of public goods. EUI Working Paper LAW 2013/04, pp.1-19.

Petersmann, E. (2017). Constitutional Constructivism for a Common Law of Humanity? Multilevel Constitutionalism as a Gentle Civiliser of Nations, MPIL Research Paper Series No. 2017-24, pp.1-25.

Preuss, U. K. (2010). Disconnecting constitutions from statehood: Is global constitutionalism a viable concept? En P. Dobner, \& M. Loughlin (Eds.), The Twilight of Constitutionalism? (pp. 23-46). Oxford: Oxford University Press.

Pogge, T. (2010). Cosmopolitismo, Precedente, pp. 143-169.

Rodrigo, A. J. (2013). El pluralismo del constitucionalismo internacional. Anuario Español de Derecho Internacional, (29), pp. 61-109.

Rodrigo, A.J. (2014). El pluralismo radical del constitucionalismo societal: La fragmentación constitucional. Revista electrónica de Estudios Internacionales, (27), pp.1-16.

Rodrigo, A.J. (2018). La constitución invisible de la comunidad internacional. Anuario Español de Derecho Internacional, 34, pp. 51-85. 
Rubenfeld, J. (2004). Unilateralism and constitutionalism. New York University Law Review, 79(6), 1971-2028.

Santiago, R. (2009), Ciudadanía cosmopolita y globalización. Una revisión del pensamiento kantiano, Universitas. Revista de Filosofía, Derecho y Política (9) (2009), pp. 5-20.

Scheffler, S. (1999). Conceptions of cosmopolitanism, Utilitas 11 (3) (1999), pp. 255276.

Schwöbel, C. (2010). Organic global constitutionalism. Leiden Journal of International Law, 23(3), pp.529-553.

Schwöbel, C. (2011). Global constitutionalism in international legal perspective. Leiden; Boston: Martinus Nijhoff.

Simma, B. (1994). From Bilateralism to Community Interest in International Law (Volume 250. En Collected Courses of the Hague Academy of International Law. Leiden; Boston: The Hague Academy of International Law.

Slaughter, A. (2004). A new world order. New Jersey: Princeton University Press.

Tomuschat, C. (1993). Obligations arising for States without or against their will (Volume 241). En Collected Courses of the Hague Academy of International Law. Leiden; Bristol: The Hague Academy of International Law.

Tomuschat, C. (2010). La comunidad internacional. En A. Peters, M.J. Aznar \& I. Gutiérrez (Coords.) La constitucionalización de la comunidad internacional (1st ed., pp. 93-120) Valencia: Tirant lo Blanch.

Velasco, J. C. (2013). Habermas: El uso público de la razón. Madrid: Alianza.

Waldron, J. (2012). Constitutionalism: a skeptical view, New York University Public Law and Legal Theory Working Papers, (248), pp. 1-46.

Walker, N. (2002). The idea of constitutional pluralism. Modern Law Review, 65(3), pp.317-359.

Walter, C. (2001). Constitutionalizing (inter)national Governance-Possibilities for and limits to the development of an international constitutional law. German Yearbook of International Law, 44, pp.170-202.

Wet, E. D. (2006). The international constitutional order. International and Comparative Law Quarterly, 55(1), pp.51-76.

Wiener, A., Lang, A., Tully (2012). Global constitutionalism: Human rights, democracy and the rule of law. Global Constitutionalism, 1(1), pp.1-15.

Zagrebelsky, G., (2013) Constitucionalismo, Derechos y Libertades, (29), pp. 19-38. 